\title{
ESTUDOS SOBRE LETRAMENTO: UM LEVANTAMENTO BIBLIOGRÁFICO A PARTIR DA PLATAFORMA DATACAPES ${ }^{1}$
}

\author{
STUDIES ON LITERACY: A BIBLIOGRAPHIC SURVEY \\ FROM THE DATACAPES PLATFORM
}

\author{
Fernanda Rodrigues Pigatto ${ }^{2}$, Valeria Iensen Bortoluzzi ${ }^{3}$, \\ Taís Steffenello Ghisleni ${ }^{4}$ e Graziela Frainer Knoll ${ }^{5}$
}

\section{RESUMO}

A aprendizagem da leitura e da escrita de maneira socialmente significativa, isto é, vinculada à realidade social dos estudantes, tem sido um dos desafios da escola. Pensando nisso, surgiram perspectivas que consideram a leitura e a escrita além da alfabetização, como o letramento. O objetivo deste trabalho é realizar um levantamento bibliográfico, no portal Datacapes, de pesquisas sobre letramento publicadas no último ano no Brasil. Os resultados demonstram pesquisas sobre a temática e, principalmente, a preocupação com o letramento como um instrumento que resulte na formação de leitores e escritores conscientes e críticos.

Palavras-chave: ensino; aprendizagem; letramento; alfabetização; pesquisa bibliográfica.

\section{ABSTRACT}

Learning to read and write in a socially significant way, that is, linked to the social reality of students, has been one of the school's challenges. With this in mind, perspectives emerged that consider reading and writing beyond literacy, as literacy. The objective of this work is to carry out a bibliographical survey, on the Datacapes portal, of research on literacy published in the last year in Brazil. The results demonstrate research on the subject and, mainly, the concern with literacy as an instrument that results in the formation of conscientious and critical readers and writers.

Keywords: teaching; learning; literacy; literacy; bibliographic research.

\footnotetext{
1 Artigo de pesquisa produzido em disciplina do Mestrado em Ensino de Humanidades e Linguagens.

2 Mestranda - Mestrado em Ensino de Humanidades e Linguagens da Universidade Franciscana. E-mail: fernandarodriguespigatto@gmail.com

3 Professora do Mestrado em Ensino de Humanidades e Linguagens da Universidade Franciscana. E-mail: valeria.bortoluzzi@ gmail.com

4 Professora do Mestrado em Ensino de Humanidades e Linguagens da Universidade Franciscana. E-mail: taisghisleni@, yahoo.com.br

5 Professora do Mestrado em Ensino de Humanidades e Linguagens da Universidade Franciscana. E-mail: graziela.knoll@, ufn.edu.br
} 


\section{INTRODUÇÃO}

Em algum momento da história, o ser humano percebeu que poderia transmitir conhecimento a outro ser humano, algo que não podemos localizar exatamente quando aconteceu, mas que iniciou com os primórdios da humanidade. A história da educação nos faz imaginar que isso começou de uma maneira intuitiva e natural, com as crianças aprendendo com os mais velhos por meio da observação, da mesma forma como fazem os animais. Daquela época para os tempos atuais, as civilizações evoluíram e instituíram seus meios formais de educação, fazendo evoluir a própria construção do conhecimento.

Segundo Gadotti (2000, p. 4), a evolução da educação ocorre de uma maneira em que perspectivas e abordagens se sobrepõem, assim, "tanto a concepção tradicional de educação quanto a nova, amplamente consolidadas, terão um lugar garantido na educação do futuro". Essas abordagens concebem educação como o processo necessário ao desenvolvimento individual, algo que, no cenário contemporâneo, se desloca do individual para o social. Há, ainda, para o autor, o papel das novas tecnologias na transformação da educação, que passou a incluir o desenvolvimento do pensamento crítico, com a condição de que, para isso, é preciso ter domínio sobre metodologias, tecnologias e linguagens.

No Brasil, para uma melhor compreensão da atuação da escola, é fundamental mencionar as tendências pedagógicas, que nos fazem refletir sobre como a escola prepara os alunos para desempenharem papéis sociais, no caso das tendências liberais, e sobre como a escola possibilita a compreensão da realidade histórico-social, assumindo um caráter pedagógico e político ao mesmo tempo (LIBÂNEO, 1990). No primeiro caso, segundo explica o autor, as tendências pedagógicas liberais não consideram as desigualdades sociais como relevantes, pois o foco é, sobretudo, a aptidão individual do estudante. Já as tendências progressistas analisam de forma crítica a realidade social e colocam o sujeito em uma posição em que o aprendizado só ocorre a partir dessa compreensão. Ainda no primeiro grupo, estão incluídas a tendência "tradicional", a "renovada progressivista", a "renovada não-diretiva" e a "tecnicista"; enquanto no segundo, há a tendência "libertadora", a "libertária" e a "crítico-social dos conteúdos". As tendências liberais podem ser assim resumidas, segundo Libâneo (1990):

a) Tendência liberal tradicional - destaca o ensino humanístico, de cultura geral, e o aluno é ensinado a atingir sua realização por meio de seu próprio esforço, sem considerar diferenças de classe e realidade social dos estudantes. O ensino de língua portuguesa considera a linguagem como expressão do pensamento e a criança com as mesmas capacidades de um adulto (normatização linguística);

b) Tendência liberal renovada progressivista (ou pragmatista) - acentua a cultura no desenvolvimento das aptidões individuais. O educando é o foco das ações, mais que o professor, valorizando a experimentação, a descoberta e os interesses do aluno. É valorizada a autoaprendizagem, com a tomada de consciência a partir das ações do estudante, entretanto, o ensino da língua segue normatizado e sem grandes diferenças em relação à abordagem liberal tradicional; 
c) Tendência liberal renovada não-diretiva - destaca a escola na formação de atitudes, ou seja, incluindo questões psicológicas dos estudantes, visando provocar a mudança interior do aprendiz para uma adequação ao meio. No ensino da língua, não provocou grandes transformações, exceto pela defesa da auto-avaliação do estudante;

d) Tendência liberal tecnicista - salienta a importância de voltar a educação para o treinamento do indivíduo para o trabalho e suas tecnologias, com orientação para o mercado. No ensino da língua, o foco tornou-se a língua em sua estrutura (estruturalismo), sem considerar contexto social e variações.

Já nas tendências progressistas, ainda conforme Libâneo (1990), há as seguintes definições:

a) Tendência progressista libertadora - pedagogia freireana, que enfatiza a escola antiautoritária, com autogestão e relaciona o conhecimento às realidades e às relações sociais e de classe.

A educação é vista como prática de liberdade e de libertação da condição de oprimido;

b) Tendência progressista libertária - destaca que o saber sistematizado somente será adquirido pelo educando se for incorporado a sua experiência de vida, não pela abstração. O ensino da língua valoriza o texto produzido pelo aluno, e a leitura é vista como uma negociação de sentidos no texto; c) Tendência progressista crítico-social dos conteúdos - salienta a primazia dos conteúdos ao confrontar as realidades sociais. Assim, cabe à escola fornecer um instrumental que prepare o aprendiz para a participação ativa na sociedade democrática. O ensino parte do conhecimento que o aluno já tem, para uma síntese organizada acerca dos conhecimentos.

Essas transformações na educação seguem ocorrendo, juntamente com a compreensão e a reflexão do que é educar e ensinar. Assim, convém considerar que professor e aluno estabelecem relações de ensino e aprendizagem desde o preparo da aula até o encontro na escola. Quando falamos em professor e aluno, o que nos faz refletir é sobre o que se ensina e como se ensina determinado conteúdo, e qual o papel dos textos nesse sentido.

Para Freire (1989, p. 37), “assim como na alfabetização não nos interessa ensinar ao Povo um puro bê-á-bá, não nos interessa também, na pós-alfabetização, transferir ao Povo frases e textos para ele ir lendo sem entender". Nesse sentido, cabe ao professor refletir sobre a visão crítica que transforma a alfabetização e as práticas de letramento, para um melhor entendimento sobre o que é orientar, incentivar e guiar a busca pelos conhecimentos e o desenvolvimento de habilidades e competências. Dessa forma, conforme o autor, o professor que se propõe a ensinar sobre um determinado conteúdo, não busca obter respostas prontas, mas, antes de tudo, entender, ampliar e aperfeiçoar os saberes que serão importantes na vida cotidiana de seus alunos em fase escolar.

Em diferentes cenários ao redor do mundo, mostrou-se necessária uma concepção de desenvolvimento e ensino de língua (e linguagem) em que aprender a ler e a escrever fosse mais significativo e uma atividade vinculada à realidade do estudante. Assim, Soares (1998, p. 39-40) distingue alfabetização e letramento: 
[...] um indivíduo alfabetizado não é necessariamente um indivíduo letrado; alfabetizado é aquele indivíduo que saber ler e escrever, já o indivíduo letrado, indivíduo que vive em estado de letramento, é não só aquele que sabe ler e escrever, mas aquele que usa socialmente a leitura $\mathrm{e}$ a escrita, pratica a leitura e a escrita, responde adequadamente às demandas sociais de leitura e de escrita. (SOARES 1998, p. 39-40).

A partir do exposto, o objetivo deste trabalho é investigar de que maneira o letramento como perspectiva de ensino da língua vem sendo utilizado no Brasil em trabalhos recentes. Para tanto, será realizada uma pesquisa qualitativa, com método de levantamento bibliográfico, a partir de uma busca na plataforma Datacapes (2019-2020). Este estudo se justifica para uma compreensão acerca das contribuições da perspectiva de letramento no ensino, considerando sua difusão nos últimos anos, em que passaram a ser exploradas diversas formas de letramento (letramento midiático, letramento multimodal, letramento digital, etc.). Neste artigo, o tema aqui abordado está estruturado da seguinte forma: aborda-se o conceito de letramento, na sequência é apresentada a metodologia da pesquisa, são apresentados os resultados e por fim, são feitas as considerações finais do estudo.

\section{LETRAMENTO}

A busca por uma definição única para o termo letramento parece ser algo difícil, uma vez que se trata de um conceito amplo e complexo. Segundo Soares (2018, p. 63), o letramento surge em consequência da necessidade de destacar as práticas sociais ligadas ao uso do sistema de escrita, isto é, abordar a aprendizagem da linguagem em situações sociais em que a leitura e escrita estejam envolvidas. Já Mortatti (2004, p. 32), afirma que se trata de uma concepção do ensino da leitura e da escrita que indica a passagem para um sentido moderno de "alfabetização das massas".

Soares (1998) considera a alfabetização como um processo de aquisição de uma tecnologia, que é a escrita alfabética, juntamente com habilidades de uso dessa tecnologia, enquanto que o letramento é especificamente relacionado às habilidades de leitura e escrita em situações de realidade social, ou seja, nos contextos situados em que o estudante é exigido. Dessa maneira, apesar de serem conceitos diferentes, ambos se conectam e complementam, a alfabetização como a aquisição de uma tecnologia e habilidades iniciais de uso, e o letramento como um aprendizado de habilidades socialmente relevantes para cada contexto.

Seguindo essas perspectivas, o letramento é um conceito importante para ser inserido nas escolas, algo que parece habitual no processo de alfabetização dos estudantes, mas que, muitas vezes, não acontece de maneira vinculada com a realidade social. Como Soares (2018) explica, trata-se de ultrapassar o mundo da escrita e leitura para alcançar as práticas dos sujeitos em relação à sociedade em que vivem. Assim, os conceitos dessas autoras brasileiras pode ser sintetizado da seguinte forma: a) o letramento envolve as práticas sociais de leitura e escrita e a aprendizagem de um sistema de escrita (SOARES, 2018); b) o letramento volta-se para o conjunto de práticas sociais em que os indivíduos se 
envolvem, conforme as demandas da realidade social, com as habilidades e os saberes que possuem (MORTATTI, 2004). Dessa forma, ao trabalhar com textos, seguem sendo exploradas as características do letramento e seus objetivos voltados para lidar com a linguagem no cotidiano. Os textos são recursos inseridos no ambiente alfabetizador de crianças nos anos iniciais do Ensino Fundamental.

Para Soares (2002), ao priorizar a perspectiva de letramento, entende-se que a alfabetização tem outra dimensão de significados:

\begin{abstract}
As pessoas se alfabetizam, aprendem a ler e a escrever, mas não necessariamente incorporam a prática da leitura e da escrita, não necessariamente adquirem competência para usar a leitura e a escrita, para envolver-se com as práticas sociais de escrita: não leem livros, jornais, revistas, não sabem redigir um ofício, um requerimento, uma declaração, não saber preencher um formulário, sentem dificuldade para escrever um simples telegrama, uma carta, não conseguem encontrar informações num catálogo telefônico, num contrato de trabalho, numa conta de luz, numa bula de remédio (SOARES, 2002, p. 46).
\end{abstract}

Portanto, o letramento é muito mais que um processo escolar de ler (decodificar), escrever (codificar) e interpretar, ou seja, deve ser combinado com a compreensão da leitura e da escrita como processos sociais, considerando a linguagem em uso. Isso significa que muitas pessoas alfabetizadas até conseguem ler, mas não compreendem o sentido do que leem. No caso da leitura, há pessoas que leem com dificuldade ou facilidade, porém sem entender exatamente a mensagem em termos de conteúdo ou função em termos de propósito.

Pode-se exemplificar a interferência das pessoas na codificação, decodificação e distorção na transformação do dado em informação e da informação em conhecimento com o seguinte exemplo:

\footnotetext{
Diferentes pessoas frente a um mesmo fato tendem a interpretá-lo de acordo com seus modelos mentais, que os levam a percebê-lo de forma diferente: um carro BMW, último tipo, conversível, zero quilômetro, totalmente destruído em um acidente no qual o motorista bateu em uma árvore centenária derrubando-a, pode ser codificado, decodificado e distorcido das seguintes maneiras. Algumas pessoas serão levadas a decodificar as informações baseadas em seus valores materiais: logo um carro tão caro! Será que ele está segurado? Enquanto outras pessoas com valores humanos mais aguçados terão seu foco no seu humano: será que o acidente resultou em feridos? Outras pessoas com interesses ecológicos ainda terão suas atenções voltadas ao destino da árvore centenária: logo nessa árvore! Não poderia ter sido em uma outra BMW? (ANGELONI, 2003, p. 12).
}

No processo de aprendizagem, é o contexto social que incentiva o interesse da criança em aprender, independentemente da educação formal, pois a criança só aprende aquelas atividades que parecem fazer sentido na experiência. Contudo, se dá importância o que diz Soares (2003a), ressaltando que a alfabetização como parte constituinte da prática de leitura e escrita não pode ter sua especificidade desprezada, ou seja, não deve ficar diluída no processo de letramento. Sendo assim, alfabetização é um trabalho complexo e muito amplo que se une tempo, propõe aos alunos o saber, que não é apenas ensinar a ler e a escrever através de um método apenas. 
A alfabetização teria que partir do pressuposto de centralizar o letramento, dando ênfase a uma aprendizagem inicial de mundo real em que ler e escrever desempenham seus papéis. Aprendizagens são "sempre retomadas por sujeitos em interação e movidas por interesses práticos no mundo em que vivem" (MARQUES, 1993, p. 110), assim, o diálogo entre dois ou mais indivíduos, a conversa e discussão entre as pessoas atendem, muitas vezes, à necessidade social de interação. Por outro lado, o diálogo é uma obra literária, em prosa ou em verso, em que é simulada uma conversação ou controvérsia entre dois ou mais personagens.

Nesse sentido, cabe ao professor proporcionar práticas significativas e coesas, bem como estimular e seduzir o aluno com livros e leituras compreensíveis e prazerosas para sua vivência naquele momento de vida. Para que isso aconteça, é preciso entender o conceito de letramento de acordo com os princípios de ensino-aprendizagem da escola.

Para Kleiman (2008), o ensino às séries iniciais na escola concentra os maiores desafios, pois a criança, ao mesmo tempo que deve ter a sua autodescoberta do mundo preservada, necessita evoluir na aquisição da língua materna. Nesse estágio, o desenvolvimento da língua está conectado com o desenvolvimento da criança e de seu pensamento, o que varia de indivíduo para indivíduo. Segundo a autora, isso acontece, "em relação às mudanças sociocognitivas, isto é, dos esquemas de conhecimentos e representações mentais, o professor precisaria de muita clareza sobre o que está envolvido nessa mudança, qual o objetivo de aprendizagem, e como ele pode ser construído pelo aluno" (KLEIMAN, 2008, p. 178). Sendo assim, o professor precisa vincular o que é desenvolvido e praticado na sala de aula com a realidade e o estágio de desenvolvimento do estudante, pensando no que é significativo para esse.

Aprender a língua torna-se bem mais do que uma transmissão de conhecimentos ou aprendizado de códigos de leitura e de escrita, pois afeta toda a vida da criança, abrangendo inclusive o seu interesse na leitura e na escrita, que precisa ser estimulado desde cedo. Logo nos primeiros contatos da criança com esse aprendizado, é conveniente fazer o aprendiz explorar suas próprias histórias e descobertas, experimentando a comunicação com os outros.

Sem dúvida, faz parte da evolução desse aprendizado ter mais habilidade de lidar com as atividades de leitura e escrita. Assim, alfabetização e letramento são processos complementares e que não cessam em desenvolvimento, pelo contrário, continuam sendo aperfeiçoados ao longo da vida.

Letramento está diretamente relacionado com a língua escrita e seu lugar, suas funções e seus usos nas sociedades letradas, ou, mais especificamente, grafocêntricas, isto é, sociedades organizadas em torno de um sistema de escrita e em que esta, sobretudo por meio do texto escrito e impresso, assume importância central na vida das pessoas e em suas relações com os outros e com o mundo em que vivem (MORTATTI, 2004, p. 98).

O professor alfabetizador que realiza suas atividades pedagógicas tendo em vista o letramento investe em brincadeiras, vivências, experiências e formas de comunicação que o próprio aluno pode trazer para o ambiente da escola, além das situações que ele mesmo planeja. Assim, a criança vai 
sendo inserida em um mundo em que as ideias letradas podem se desenvolver de forma muito mais natural ou integradora, abrangendo, até mesmo, a família, já que o aprendizado continua nos diferentes ambientes e com as pessoas que com ela interagem diariamente. Nesse sentido, percebe-se o quanto é favorável entender alfabetização e letramento como enfoques que se complementam na vida do sujeito aprendiz. E à escola cabe tornar as práticas de leitura e escrita significativas, entendidas muito mais do que uma união de letras e fonemas, mas voltadas à elaboração de hipóteses, à interpretação crítica de textos e a saber agir por meio da linguagem (oral ou escrita) em diferentes situações.

\section{METODOLOGIA}

O trabalho tem abordagem qualitativa, com pesquisa de caráter exploratório e método de levantamento bibliográfico. Para Minayo (2001), a pesquisa qualitativa trabalha com o universo de significados, motivos, aspirações, crenças, valores e atitudes, o que corresponde a um espaço mais profundo das relações, dos processos e dos fenômenos que não podem ser reduzidos à operacionalização de variáveis. Segundo Cervo e Bervian (1983, p. 55), as pesquisas bibliográficas "buscam conhecer e analisar as contribuições culturais ou científicas do passado existentes sobre um determinado assunto, tema ou problema".

A bibliometria "como metodologia iniciou-se com a finalidade de avaliar e entender o desempenho das atividades de produção científica acadêmica, utilizando para tanto uma quantidade de dados, referentes ao período pesquisado, para a extração das informações necessárias” (WOLFRAM, 2017). Dessa forma, a bibliometria assume um papel essencial na análise do comportamento da produção científica e possibilita o aumento da visibilidade das novas fontes de informações e conhecimentos, partindo da avaliação, teses, dissertações e demais publicações da pesquisa científica. Para a pesquisa bibliográfica, o primeiro passo foi acessar a plataforma Datacapes e realizar uma pesquisa dos trabalhos sobre o tema.

Foi feita uma busca, a partir da palavra letramento, no portal de periódicos Datacapes, selecionando-se os anos de 2019 a 2020 para a seleção dos artigos. Como critérios de seleção, foram excluídos da coleta artigos publicados em outro idioma que não fosse a Língua Portuguesa, os artigos duplicados ou de acesso indisponível. Feita a seleção, foi elaborado um quadro para o levantamento, com título do artigo, periódico, ano de publicação, objetivo, metodologia e síntese dos principais resultados de cada pesquisa. Em seguida, foram destacados os dados encontrados e interpretados os resultados.

\section{RESULTADOS E DISCUSSÃO}

Há uma diversidade de contextos e aplicações em que seria importante investigar o letramento. E esse interesse por outras aplicações além da alfabetização advém de um contexto em que, cada vez mais, grupos sociais, funções profissionais e minorias atentam para o uso da escrita como forma de empoderamento e ação. 
As abordagens sócio-históricas que embasam os estudos do letramento e da linguagem evidenciam a importância do contexto social e das singularidades dos sujeitos aprendizes para a compreensão da leitura e da escrita. Devido à ampla diversidade de realidades e de pessoas, com o tempo, vários estudiosos perceberam que ensinar uma língua e as práticas sociais que a acompanham não é questão somente de padronizar usos e normas, mas de entender os processos socioculturais desempenhados na sociedade, em diferentes situações e com propósitos específicos, para, então, entender como agir na e pela linguagem.

Os dados selecionados para cada artigo foram apresentados no Quadro 1.

Quadro 1: Artigos publicados nos últimos dois anos (2019 e 2020).

\begin{tabular}{|c|c|c|c|c|c|}
\hline $\begin{array}{c}\text { Título } \\
\text { do Artigo }\end{array}$ & Periódicos & $\begin{array}{c}\text { Ano } \\
\text { Publicação } \\
\end{array}$ & Objetivo & Método de Pesquisa & $\begin{array}{l}\text { Principais } \\
\text { Resultados }\end{array}$ \\
\hline $\begin{array}{l}\text { Mudança Social } \\
\text { também se } \\
\text { faz com uma } \\
\text { Educação na } \\
\text { Leitura e na } \\
\text { Escrita voltada } \\
\text { para o Letra- } \\
\text { mento }\end{array}$ & $\begin{array}{l}\text { Revista Internacio- } \\
\text { nal de Apoyo a la } \\
\text { Inclusión, Logope- } \\
\text { dia, Sociedad y } \\
\text { Multiculturalidad. } \\
\text { Volumen 5, Número } \\
\text { 2, Junio 2019, } \\
\text { ISSN: } 2387 \text {-0907. } \\
\text { DOI: https://dx.doi. } \\
\text { org/10.17561/riai. } \\
\text { v5.n2.1 }\end{array}$ & 2019 & $\begin{array}{l}\text { Conhecer épocas, } \\
\text { diferentes e observar a } \\
\text { transformação social da } \\
\text { sociedade, das culturas } \\
\text { e das descobertas mé- } \\
\text { dicas. }\end{array}$ & $\begin{array}{l}\text { Metodologia descritiva, } \\
\text { que se baseou nas ex- } \\
\text { periências e pesquisas } \\
\text { feitas pelos autores } \\
\text { mencionados neste arti- } \\
\text { go como Grossi, Freire } \\
\text { e Magda. }\end{array}$ & $\begin{array}{l}\text { Aumentaram as perguntas } \\
\text { sobre dúvidas a respeito do } \\
\text { significado de palavras des- } \\
\text { conhecidas por eles, como } \\
\text { também em livros mais } \\
\text { antigos a curiosidade de } \\
\text { entender a escrita de certas } \\
\text { palavras que lhes parece } \\
\text { estranhas, mas na realidade } \\
\text { fazem parte da transforma- } \\
\text { ção da nossa língua. }\end{array}$ \\
\hline
\end{tabular}




\begin{tabular}{|c|c|c|c|c|c|}
\hline $\begin{array}{l}\text { A leitura lite- } \\
\text { rária como lugar } \\
\text { de liberdade em } \\
\text { um ambiente de } \\
\text { encarceramento: } \\
\text { possibilidade de } \\
\text { reflexão sobre } \\
\text { problemas } \\
\text { sociais. }\end{array}$ & $\begin{array}{l}\text { Acta Scientiarum. } \\
\text { Language and } \\
\text { Culuture, v. 42, } \\
\text { e47837, } 2020\end{array}$ & 2020 & $\begin{array}{l}\text { Contribuir com o } \\
\text { letramento literário de } \\
\text { adolescentes encarce- } \\
\text { radas em uma Unidade } \\
\text { de Internação Feminina } \\
\text { (UIF). }\end{array}$ & $\begin{array}{l}\text { Estudo de caso, com } \\
\text { realização de grupo e } \\
\text { seleção de um livro, } \\
\text { de modo que a leitura } \\
\text { proporcionasse reflexão } \\
\text { sobre suas vidas. }\end{array}$ & $\begin{array}{l}\text { Os resultados indicaram in- } \\
\text { teresse por parte das internas } \\
\text { na leitura literária e na es- } \\
\text { crita de texto autobiográfico, } \\
\text { memorialístico, com base } \\
\text { nas lembranças pessoais dos } \\
\text { lugares onde moravam a } \\
\text { partir do imbricamento entre } \\
\text { literatura e vida real. }\end{array}$ \\
\hline $\begin{array}{l}\text { O Estado da } \\
\text { Arte da Produ- } \\
\text { ção Acadêmica } \\
\text { sobre o Letra- } \\
\text { mento Digital } \\
\text { na Formação } \\
\text { Docente }\end{array}$ & $\begin{array}{l}\text { Revista Ibero-Ame- } \\
\text { ricana de Estudos } \\
\text { em Educação, } \\
\text { Araraquara, v. 15, n. } \\
\text { 1, p. 125-145, jan. / } \\
\text { mar. 2020. e-ISSN: } \\
\text { 1982-5587. }\end{array}$ & 2020 & $\begin{array}{l}\text { Realizou um levantamen- } \\
\text { to de teses e dissertações } \\
\text { dos cursos de pós-gra- } \\
\text { duação stricto sensu das } \\
\text { Instituições de Ensino } \\
\text { Superior do estado de } \\
\text { Minas Gerais, no período } \\
\text { de } 2000 \text { a junho de } \\
2017 \text {, com o objetivo de } \\
\text { identificar quais as ten- } \\
\text { dências que as produções } \\
\text { acadêmicas apresentam } \\
\text { nas investigações sobre } \\
\text { letramento digital na } \\
\text { formação de professores. }\end{array}$ & $\begin{array}{l}\text { Pesquisa bibliográfica, } \\
\text { analítica e descritiva, } \\
\text { numa perspectiva me- } \\
\text { todológica do Estado } \\
\text { do Conhecimento ou } \\
\text { Estado da Arte, sobre } \\
\text { letramento digital na } \\
\text { formação de profes- } \\
\text { sores. }\end{array}$ & $\begin{array}{l}\text { Como resultado tem-se que } \\
\text { as pesquisas são ainda inci- } \\
\text { pientes ao tratar do tema e } \\
\text { até mesmo superficiais, em } \\
\text { alguns casos misturando o } \\
\text { determinismo e o relativis- } \\
\text { mo tecnológico. }\end{array}$ \\
\hline $\begin{array}{l}\text { Plano Nacional } \\
\text { de Educação } \\
\text { (2014-2024): } \\
\text { Reflexões sobre } \\
\text { a Alfabetização } \\
\text { e o Letramento. }\end{array}$ & $\begin{array}{l}\text { Revista on line de } \\
\text { Política e Ges- } \\
\text { tão Educacional, } \\
\text { Araraquara, v. } 24 \text {, } \\
\text { n. 1, p. 37-54, jan. / } \\
\text { abr., 2020. e-IS- } \\
\text { SN:1519-9029. } \\
\text { DOI: https://doi. } \\
\text { org/10.22633/rpge. } \\
\text { v24i1.12793 }\end{array}$ & 2020 & $\begin{array}{l}\text { Discutir a meta } 5 \text { do } \\
\text { PNE, que institui que } \\
\text { a alfabetização das } \\
\text { crianças deve aconte- } \\
\text { cer, no máximo, até o } \\
\text { terceiro ano do ensino } \\
\text { fundamental. }\end{array}$ & $\begin{array}{l}\text { Promover o desenvol- } \\
\text { vimento de tecnologias } \\
\text { educacionais e de } \\
\text { práticas pedagógicas } \\
\text { inovadoras que asse- } \\
\text { gurem a alfabetização } \\
\text { e a aprendizagem das } \\
\text { crianças, consideradas } \\
\text { as várias abordagens } \\
\text { metodológicas e sua } \\
\text { efetividade nos diferen- } \\
\text { tes contextos de ensino. }\end{array}$ & $\begin{array}{l}\text { Os resultados das avalia- } \\
\text { ções oficiais, bem como } \\
\text { dos pareceres internos de } \\
\text { avaliações das escolas e do } \\
\text { Censo Escolar, revelam que } \\
\text { as dificuldades do estudante } \\
\text { ao aprender a ler e escrever, } \\
\text { atinge mais da metade dos } \\
\text { alfabetizandos de até oito } \\
\text { anos de idade. }\end{array}$ \\
\hline
\end{tabular}

Fonte: elaboração própria.

Há uma recorrência de artigos envolvendo letramento no ensino de língua materna, em relação à alfabetização. Já em relação a outras aplicações dessa abordagem, como letramento científico-acadêmico ou letramento digital, são menos encontradas, o que sugere que essa abordagem ainda é recente e tem muito a ser explorada em diversos campos de atividades, já que as pessoas lidam com textos nos mais diversos contextos, não somente no ensino de língua materna.

Além disso, quanto aos resultados obtidos em cada uma das pesquisas elencadas, destacam-se os seguintes pontos: 
- O artigo "Mudança Social também se faz com uma Educação na Leitura e na Escrita voltada para o Letramento" é um exemplo de um dos principais benefícios da abordagem de letramento, referente ao vínculo entre aprendizado de linguagem e mudança social ou transformação de realidades sociais;

- O artigo "Adaptações curriculares na construção de práticas de letramento para alunos surdos" coloca em questão a falta de preparo docente para o letramento bilíngue de aprendizes surdos; - O artigo "Estratégias de Letramento voltados à intervenção fonoaudiologia em pessoas com Síndrome de Down" coloca em foco o letramento como uma perspectiva útil não só para a produção textual escrita, mas para a aquisição da oralidade;

- O artigo "A leitura literária como lugar de liberdade em um ambiente de encarceramento: possibilidade de reflexão sobre problemas sociais" ressalta a relação do letramento, neste caso, literário, voltado à consciência crítica e à expressão de liberdade por meio da autobiografia, indicando a importância de uma perspectiva de linguagem como "local" de empoderamento; - O artigo "O Estado da Arte da Produção Acadêmica sobre o Letramento Digital na Formação Docente" indica a grande lacuna de letramento digital dos docentes brasileiros, incluindo a carência de pesquisas nessa área, já que ser letrado em tecnologias digitais vai além de simplesmente saber seu uso;

- O artigo "Plano Nacional de Educação (2014-2024): reflexões sobre a alfabetização e o letramento" revelam dificuldades de leitura e escrita bastante frequentes e profundas em a maioria dos estudantes em fase de alfabetização.

Ainda, conforme os dados coletados, há artigos bibliográficos, como "O Estado da Arte da Produção Acadêmica sobre o Letramento Digital na Formação Docente”, e pesquisas de campo, como "Mudança Social também se faz com uma Educação na Leitura e na Escrita voltada para o letramento". A maioria das pesquisas encontradas enfoca o ensino básico (níveis fundamental e médio) e o ensino superior. Nesse sentido, destacamos os artigos “Adaptações curriculares na construção de práticas de letramento para alunos surdos" e "Estratégias de Letramento voltados à intervenção fonoaudiologia em pessoas com Síndrome de Down", que envolveram participantes diferentes da área de ensino de Língua Portuguesa, como LIBRAS e intervenção fonoaudiológica na aprendizagem. Isso demonstra que prevalece o uso da abordagem de letramento na educação formal básica, porém já surgem aplicações em outras áreas.

Houve também uma preocupação de destaque nos diferentes artigos com a distinção entre alfabetização e letramento, como ocorre no artigo "Plano Nacional de Educação (2014-2024): Reflexões sobre a Alfabetização e o Letramento", em que foi citado o conceito de alfabetização e seu uso dos anos de 1980 até os dias atuais. Essa distinção mostra-se importante, dessa forma, para a compreensão do próprio letramento. O aprofundamento do conceito de letramento parece requerer essa diferenciação entre ensinar a ler e a escrever de forma socialmente relevante e, por outro lado, aprender a codificar e decodificar textos escritos. 
Dentre os aspectos em comum nos artigos encontrados, destacam-se:

- A aplicação da abordagem de letramento a um contexto específico;

- A valorização do contexto de ensino para a aprendizagem da língua e para as propostas didáticas encontradas;

- O ensino conectado, ou seja, as relações entre textos e tecnologias;

- A preocupação com a realidade do estudante, ou seja, com o ponto de vista do sujeito aprendiz.

Carecem ainda de estudo algumas questões que podem ser exploradas, tais como: o letramento na perspectiva do professor, ou seja, como o docente entende, utiliza ou avalia a perspectiva de letramento? De que forma o letramento pode ser trabalhado de maneira interdisciplinar na escola? E quais as relações que podem ser feitas, além da alfabetização, entre o letramento e outras abordagens tradicionais de ensino?

Haja vista que o letramento corresponde ao processo de aquisição e desenvolvimento de habilidades de leitura e escrita, sabe-se que o letramento envolve aplicações variadas e, inclusive, pode ser associado com diferentes tipos de letramento: por exemplo, alguém que tem dificuldade no letramento durante a fase de alfabetização pode estender essa dificuldade ao longo da vida, o que o acompanhará fora da sala de aula, em contextos sociais em que a leitura e a escrita são requeridas, como em uma entrevista de emprego futuramente. O letramento enfatiza a necessidade de aprender não só a aquisição dos códigos, mas, principalmente, da função social da linguagem, para então desenvolver habilidades ligadas a contextos relevantes para o estudante. Assim, para ser competente na leitura e na produção textual (oral ou escrita), o estudante necessita ter contato com diversos gêneros textuais para ampliar seu repertório de linguagem e de textos.

\section{CONSIDERAÇÕES FINAIS}

Ao realizar esta pesquisa de levantamento bibliográfico, foi importante fundamentar teoricamente a temática de estudo para, depois, passar à exploração do conceito e suas aplicações a partir de trabalhos recentes sobre esse tema. A relação com o conceito de alfabetização é um ponto relevante para os estudos de letramento, entretanto, não é o único enfoque necessário. Sem dúvida, para o ensino de língua materna, os benefícios da abordagem são mais evidentes, mas há outros contextos de aplicação igualmente importantes, e os artigos encontrados demonstram alguns deles, como o letramento digital do professor, o letramento literário e o letramento de indivíduos surdos, por exemplo.

O letramento ajuda a desenvolver a capacidade de questionar, de criticar, de colocar em dúvida e de transformar a realidade social. Nesse sentido, deve ser valorizada, também, a formação do professor, que só poderá realizar práticas de letramento se, em primeiro lugar, souber mais sobre essa perspectiva. A alfabetização e o letramento, apesar de diferentes, não são processos autônomos, ou seja, o estudante que aprende a utilizar códigos de linguagem não deve ter esse aprendizado à parte 
do trabalho com textos, pois é lendo e produzindo textos (orais e escritos) que desenvolve habilidades de interação eficientes ou competentes. Isso significa que o letramento pode estar presente em todos os níveis de ensino e anos escolares, inclusive depois da formação do indivíduo, na sua prática profissional. A escola, por sua vez, atua como um espaço próprio para os múltiplos letramentos relevantes para a vida social. Por essa razão, deve propiciar formas de participação do estudante, trabalho com diferentes gêneros textuais e possibilidades de interação e experimentação.

\section{REFERÊNCIAS}

ANGELONI, Maria Terezinha. Comunicação nas organizações na era do conhecimento. São Paulo: Atlas, 2010.

CERVO, I.; BERVIAN, P. A. Metodologia científica: para uso dos estudantes universitários. São Paulo: McGrauw - Hill, 1983.

FREIRE, Paulo. A importância do ato de ler: em três artigos que se completam / Paulo Freire. São Paulo: Autores Associados: Cortez, 1989.

GADOTTI, Moacir. Perspectivas atuais da educação. São Paulo em Perspectiva, v. 4, n. 2, abr.-jun. /2000. Disponível em: https://bit.ly/2Zm8xpx. Acesso em: 19 jul. 2020.

MARQUES, Mario. Conhecimento e modernidade em reconstrução. Ijuí: Ed. UNIJUÍ, 1993.

KLEIMAN, Ângela. Alfabetização e Letramento. 6. ed. - São Paulo: Contexto 2011.

LIBÂNEO, José Carlos. Democratização da escola pública. São Paulo: Loyola, 1990.

MINAYO, Maria Cecília Souza. (Org.). Pesquisa social: teoria, método e criatividade. Petrópolis: Vozes, 2001.

MORTATTI, Maria do Rosário Longo. Educação e Letramento. São Paulo: UNESP, 2004.

SOARES, Magda. Letramento: um tema em três gêneros. 2. ed. Belo Horizonte: Autêntica, 2002. 
SOARES, Magda. A reinvenção da alfabetização. Revista Presença Pedagógica, Belo Horizonte, v. 9, n. 52, p. 15-21, jul./ago. 2003.

SOARES, Magda. Alfabetização e Letramento. 7. ed. 2. Reimpressão. São Paulo: Contexto, 2018.

WOLFRAM, Dietmar. Bibliometrics Research in the Era of Big Data: Challenges and Opportunities.

Bibliometria e Cientometria no Brasil: infraestrutura para avaliação da pesquisa científica na Era do Big Data, p. 91-101, 2017. 